\title{
EVADING TECHNOLOGICAL DETERMINISM IN ERP IMPLEMENTATION: TOWARDS A CONSULTATIVE SOCIAL APPROACH
}

\author{
Dr Clare Archer-Lean \\ Centre for Social Change \\ Queensland University of Technology Carseldine Campus \\ Brisbane, Queensland, Australia \\ Email: clare.archerlean@shafston.edu \\ Jo-Anne Clark \\ School of Information and Communication Technology \\ Griffith University, Nathan Campus \\ Brisbane, Queensland, Australia \\ Email: Jo-Anne.Clark@student.griffith.edu.au \\ Dr Donald Kerr \\ Department of Management \\ Griffith Business School \\ Griffith University, Logan Campus \\ Brisbane, Queensland, Australia \\ Email: d.kerr@griffith.edu.au
}

\begin{abstract}
Enterprise Resource Planning (ERP) systems are implemented in business in the hope of obtaining benefits in the form of improved communications and increased efficiency through the standardization of information technology (IT) across functional business areas. The benefits, and in some cases problems, associated with implementation have been well documented, however there is little information available on their effectiveness in a different form of organization. This paper looks at ERP implementations in Government Owned Corporations (GOC) and discusses implementation issues by looking at the way we perceive such organisations. A GOC case study is presented and explored in terms of the ERP and GOC literature in the context of existing social research approaches. This paper examines why end users in a GOC appear to be neither complying with, nor fully exploiting the potential of the ERP. The paper contends that discourses by staff at the operational level are different to that of staff at the managerial level. The paper also confirms previous research stating the importance of end user input for effective IT systems and ERP implementation processes.
\end{abstract}

\section{INTRODUCTION}

Over the past decade, the number of organizations adopting ERP (Enterprise Resource Planning) systems has increased significantly (Beekhuyzen, 2006). The ERP promise involves a standardisation and streamlining of all business functions across the organisation to enable better communication, thereby increasing efficiency (Davenport, 1998, Scheer \& Habermann, 2000, Bagchi, Kanungo \& Dasgupta, 2003). This streamlining also occurs at an external level, in that a motivating factor in implementing ERP is the need to standardise the enterprise's processes as they 
are benchmarked against other corporations, thereby increasing their own competitiveness (Scavo, 2005). This paper builds on Hobson et. al.'s statement that past ERP research has been primarily technologically determinist and that the research has largely ignored what these authors term "the social system" (Hobson, et.al, 2005:3). An Australian Government Owned Corporation provides a fruitful case site to explore the problems of a technological determinist implementation that fails to synthesize with the existing social system. A cultural analogy is used to allow the rethinking of the causes of ERP implementation failure. This paper attributes ERP failure to a clash between the push to use technology to determine the nature of an organisation rather than as a tool of an existing and rich culture. The key area of the CASE explored as evidence for the source of implementation difficulties is the training stage of implementation. Some multi-disciplinary approaches are employed to provide insightful ways to improve the implementation process of ERP systems.

\section{CONTEXT AND BACKGROUND}

\section{ERP definitions and existing research}

ERP can be viewed as a pre-packaged software product that can be bought off-the-shelf and then tailored by an organisation in order to integrate and share its information and related business processes within and across functional areas (Davenport, 1998). The ERP can replace an organisation's disparate systems with a tightly integrated system of standard software modules that embodies all functional areas (Ross, 1999; Skok \& Döringer, 2001). This type of multifaceted system promises a seamless integration of company wide information which includes financial, accounting, human resource, supply chain and customer information (Davenport, 1998); although it demands a large technical architecture that has huge storage needs, networking requirements and specific hardware/software requirements (Scheer \& Habermann, 2000). The reasons driving such wide spread ERP implementation are clear. According to Skok \& Döringer (2001:3) the key drivers for the adoption and growth of ERP can be attributed to increased globalisation of businesses, business process reengineering, a focus on standardisation of processes e.g. ISO9000, scaleable and flexible emerging client/server infrastructures, the trend for collaboration among software vendors and the rapid emergence of E-Business. ERPs are a way for organisations to replace their ageing legacy systems, improve strategic business advantage, and improve system architectures. (Markus, Petrie \& Axline, 2000). The clear intent to replace old IT systems can potentially permeate into an attempt to replace the wider organizational culture. The fixed requirements can also cause problems for end users in terms of adoption and ERP usage as by its very nature ERP imposes its own logic on an organisation's existing structure (Davenport, 1998). Information systems implementation in general has been, as reported in the research, notoriously difficult. So it is therefore not surprising that ERP implementations are especially difficult to implement, due to their size, scope and complexity (Alvarez and Urla, 2002). Some of the most serious problems associated with ERP implementation include limited functionality, a narrow scope for decision support, upgrade and maintenance difficulties and total cost of ownership (Markus, Petrie \& Axline, 2000). Along with the ERP's track record of unsuccessful implementations is the often overlooked issue of end user support. End user's needs are frequently missed by technological solutions (Beekhuyzen, 2006). Throughout this paper, the end user's role in ERP implementations is discussed.

Hobson et al. (2005) contend that the existing heavily positivist research into ERP implementation is inadequate as it does not take into account the social system of the end user. Their study supported this hypothesis with a literature review of the use of key words associated with a positivist outlook. This paper seeks to understand why end users in a GOC are neither complying with nor fully exploiting the potential of ERP. The CASE study is selected because of the demonstrable history of 
problems in ERP implementation within non-standard commercial organisation, particularly the Government Owned Corporations (GOC). ${ }^{4}$ The authors suggest that a multi-faceted qualitative focus is necessary in researching the issues involved in ERP implementation. This paper seeks to begin discussion of ERP implementation issues in GOC by changing the way we perceive such organisations.

\section{Government Owned Corporations and ERP implementation}

ERP systems are ideally placed to service the private sector. A brief overview of the historical development of ERP suggests that its foundations lie heavily in assisting manufacturing companies in planning and scheduling (The United States Army, 2005). ${ }^{5}$ In addition, some of the most noteworthy Australian success stories in ERP implementation feature private sector companies rather than public sector organisations. For example, Meadow Lea's implementation of ERP facilitated the fast tracking of data on the company's grocery outlet sales across the nation. This information hitherto unavailable to the company - was vital in effective financial and marketing strategies. ERP can facilitate the development of strategic alliances. For example, ERP standardisation allowed the formation of the Meadow Lea / Canadian Canola Association and International Fats and Oils companies' alliance (Dooley, 2004).

Current political trends of economic rationalism require management of GOC to increasingly draw on the competitive success strategies of the private sector, including use of advanced Information Systems, specifically the ERP, to streamline both internal data processing and retrieval and external business engagements. But GOC are remarkably different organisations to private sector corporations and therefore require information systems or at least end user training and implementation strategies that are tailored to their specific needs.

The Government Owned Corporation (GOC) is a special case in ERP implementation because of the inherent paradoxical properties of the GOC. In previous eras, industries such as energy and transport provision existed primarily in the public sector, in clear distinction to the private sector. Currently, services are provided by GOC that operate in terms of private process and financial impetus but also through public management and guidelines. A GOC is defined as a corporatised commercial entity that is freed from the budget sector but that is managed by governmental ministers (Queensland's Government Owned Corporations Act, 1993). This type of corporation acts as a publicly-owned trading enterprise which conducts activities and provides services in a commercially-orientated environment (Office of Government Owned Corporations, 2003).

The office controlling GOCs was established by the Queensland Government in 2000. The role of this office was to "manage the State Government's shareholding relationship with GOCs". The office is responsible for:

- negotiating outcomes of the annual performance contract or Statement of Corporate Intent (SCI) as well as the five-yearly Corporate Plan;

- monitoring the performance of GOCs and determining dividend payments;

- $\quad$ assessing major investment proposals;

- GOC Board appointments;

- $\quad$ ensuring GOC compliance with relevant Queensland Government policies; and

\footnotetext{
${ }^{4}$ Identity protected.

${ }^{5}$ The MRP and MRP2 systems were specifically designed for the manufacturing sector.
} 
- administering the Government Owned Corporations Act 1993. (Government Owned Corporations Act, 1993).

This list demonstrates the GOC yoking of financial viability and Government policy compliance; suggesting that at any given time a GOC is subject to a number of potentially contradictory impulses. While increasing reporting requirements and privatisation do put pressure on GOC to be defined through their commercial entity, GOC have different requirements in terms of profit to a lone standing private enterprise. A recent state government report has revealed that many GOC are in fact running at a loss rather than yielding any profit returns. Administrative functions have been blamed for the long term lack of solvency of the corporations involved (Smart Business Smart Queensland, Commerce Queensland Blueprint: Smart Policy - Smart Business, 2005).

These different financial operations are due to the fact that GOC are also crucial service providers for the public interest. A GOC must therefore consider employee rights, public interest and voter backlash and profitability: like private companies, they engage in profit-seeking commercial activity, often in competition with private sector businesses. Like public sector agencies, they are required to execute government policies, often in the form of delivering non-commercial services or "community service obligations" (Government Business Enterprises and Public Accountability through Parliament, 1999-2000). This tension between public and private drives makes fast tracked changes more complicated than would be the case in a purely private corporation (Brown, Ryan, and Parker 2000).

In ERP adoption and training of end users, there is no facility for gradual change and the push for fast change actually results in freezing of the process. As stated in Davenport (1998) it is inherent in the very nature of an enterprise system that is imposes its own logic and structure on a company's strategy, organization, and culture. It can push a company towards full system integration when this may not be in the organization's best interest (Davenport, 1998). The public sector also operates at a much slower rate because of the structural and bureaucratic levels necessary in such organizations: "If a company rushes to install an enterprise system without first having a clear understanding of the business implication, the dream of integration can quickly turn into a nightmare" (Davenport, 1998:121).

A final complicating factor in the implementation of ERP in GOC lies in their service areas. Most obviously, state and national GOC are involved in the two areas of energy and transport. These industries are very mature and often involve an organisational structure and culture with deeply entrenched ideologies and practices. So a GOC is split in terms of its corporate identity. It is public and private; mature and culturally established yet desirous of technological innovation and change. It is fundamentally categorised by its incorporation of a number of different practices and motivations held in delicate balance. The ERP technological determinist push for institutional transformation to the requirements of the technology, potentially threatens the tropes that categorise the organisation itself.

\section{The Research Site}

The specific identity of the CASE study has not been revealed because of the ethical necessity to comply with anonymity clauses implicit in the research project. The GOC will therefore be referred to simply as CASE.

The CASE organisation used for this study is a large GOC operating at a State level. Like all essential utility services within Australia, the CASE has been operating for well over a century and is 
a very mature industry. The CASE organisation has a global reputation for providing innovative and performance driven services. It has a turnover of over \$A 2 Billion and has over 13,000 employees.

The CASE GOC had already replaced a sound operational system with SAP R/2. Recently management made the decision to upgrade to SAP $\mathrm{R} / 3$. The initial motivation for this implementation was to facilitate new reporting requirements and the implementation process involved conversion from SAP R/2 to SAP R/3 for 6,000 users. The modules involved in the implementation were: financial; material management; logistics; forecasting and planning; materials resources planning (MRP); human resources; information systems, including executive information systems; project management; and office integration.

The objective of the research project was to find ways to optimize the supply chain of the GOC and to this end, 33 interviews with key stakeholders along the entire supply chain were conducted to determine important elements in each individual's job and how they related to the supply chain in its entirety. Interviews ranged from human resource personnel all the way to operational staff and included the supply chain partners such as suppliers of raw materials and manufactures. Over 500 pages of transcripts were recorded.

\section{ANALYSIS OF CASE: SOCIAL SYSTEMS VS TECHNOLOGICAL SYSTEMS}

Technological determinism is frequently a latent assumption in IT research and can be defined as a focus on the technical system and its success rather than the social system that must operate it. Many researchers "have long rejected the overly simplistic notion that technology is an autonomous force that determines the course of society" (Smith \& Marx, 1994). Whilst acknowledging the ongoing nature of this study, the key goal of this paper is to better explain end user non-compliance with ERP and open up ways of perceiving a GOC's IT implementation requirements by reexamining end users' experience. As Hobson et al. (2005) state, ERP research is frequently positivist in nature and as a consequence technologically deterministic. When the social system/end users are explored, it is in terms of their deficiencies in responding to training packages and in operation of the software. In contrast to this approach Orlikowski (1991) stresses that technology should be viewed as "the product of human action" [emphasis added].

Often ERP implementation causes so much stress on an organisation that human capabilities are unable to realistically keep up or meet its requirements, for example in the Hilton Corporations upgrade of PeopleSOFT the Vice President of the Hilton's corporation stated that "employees got paid, but only after round-the-clock efforts by the company's payroll staff. It took three weeks to completely catch up" (Anthes, 2003). The US Army Enterprise Solutions Competency Center (2006) view ERP implementation fundamentals as a plethora of requirements that "can make governance structures look more like engineering diagrams than organization charts and slow the decision making process to the point where it cannot effectively support its programs." In ERP implementations there is often a misalignment between the human/business system and the new technological system (Davenport, 1998). The authors concur with Orlikowski (1991) in her statement that technology has "a dual nature, being both constructed and enacted by human agents, as well a material force that shapes human action and social practices". To date, social focused approaches to ERP implementation exist but are limited in numbers. New social approaches will improve future use of ERP if they focus on the language of the users.

One way in which this can be done is to focus on the reports of the users themselves. Interviews then are a vital tool, if viewed through a qualitative lens (Yin, 1994). In order to avoid a positivist 
concentration on systems analysis and data collation, the language should be seen as part of an organic and dynamic social system. A positive analogy for understanding the organic and dynamic social system of the GOC is that of a series of entrenched sub-cultures. The metaphor of an organisation as a culture is not new. The perception that organisations do not simply possess cultures which must be subsumed to the larger organisational missions but actually are entrenched culture/s with shared values, beliefs, language and social systems of operation is well documented in the literature (Smircich 1983; Bright and Cooper 1993). Culture is a diverse term and must be defined. Geertz's "culture concept" emphasizes the importance of historically ingrained and inherited meaning carried through symbols within cultures. These patterns of symbols and linguistic tropes within culture both reflect and, importantly, shape understanding of reality (Geertz 1966 in Varenne, 2002). In the context of an organization using technology the relationship between cultural language and symbols and perception and use of the technology is clear. This is so much so that we must distinguish as Orlikowski does between the physical construction and use of technology and the social use and interpretation of technology (Orlikowski, 1991). That technology is socially constructed "by actors through the different meanings they attach to it and the various features they emphasize and use" is clear in the case with the end users' frustration in a supposedly beneficial system.

Here, we posit that the CASE GOC consists of not only diverse missions and operators, but also cultures, even sub cultures, with historically entrenched forms of communication and understanding of information. Such embedded cultural mores cannot simply be re-determined by an externally applied technological infrastructure. The impediments to implementation are a result of the technologically determinist inability to gauge the complexity of the existing culture. These complexities are largely expressed in symbolic and non-self-conscious forms which in turn shape responses to innovations within the culture. The key users of the supply chain of the ERP within the CASE Corporation each operate out of inherent values and serve particular functions while using a specific discourse and carrying out particular rituals. This was emphasized through the strong culture that existed in the GOC with the experienced "long-time workers" consistently referring to new employees as not "understanding the history and culture of the organization". These "new workers" were treated with suspicion and a certain amount of mistrust as they often referred to the need to "employ people with a higher level of education and a greater understanding of the modern corporation". The CASE does not represent a homogeneous and unified culture ready to cohesively adapt to change. ERP implementation does not take into account the intricacies of the culture and it is therefore unable to shape reality or shape itself to the existing reality, thereby failing to deliver the promised increases in effectiveness.

One of the glaring examples of the failure to synthesize ERP implementation with the existing culture of the CASE occurs within training. ERP implementation clearly requires mandatory processes to make the system operational. Like any information system's implementation it follows a chosen life cycle and there are optimal recommendations associated with the implementation stage such as planning, user training, conversion strategies and follow up (Alter, 2002). The design of the training need not be entirely determined by the technology. End user training provides an area to explore the usefulness of social focused methodology in improving ERP implementation. Much research in ERP implementation has identified lack of or insufficient training as a key barrier to success. We contend that there is only ostensible compliance, at the level of initial training and that training packages are often computerised manuals with 'successful' training achieved through the user working their way through each module. It did not take long for end users in the CASE to realize that repeated pressing of the next or enter key could speed up the process considerably without the need to learn how the system was working. People were inclined to do this because the training was not done inthe context of the every day work routine of each individual and the output 
produced during training did not relate to their own work environment. Repeated pressing of the 'enter' key ultimately leads to the end user being awarded a certificate, qualifying her/him to use ERP. This form of information transfer does not align with the entrenched forms of practical and "on the job" (CASE study data) training and communication in the pre-existing operational staff culture. The ERP training process, while it may, through the work of training organisations, attempt to find an example meaningful to the end user, ultimately is a set package that is largely mechanized hoopjumping. The users feel imposed upon rather than assisted, and as a result there is much anecdotal evidence with the CASE for ostensible rather than actual compliance with the training package.

Motivation is core part of successful implementation of any organizational change. In the CASE the staff motivation for ERP implementation is absent. There is a general feeling (revealed in interviews) that the system is ultimately about higher management and accounting compliances than ease of use and assistance for users in the supply chain. The original SAP R/2 system replaced a useable system for operational staff because management was more concerned with integrating IT resources and having a system that they could use for their own reporting requirements. It appears that management is supporting a technological determinist approach that is impeding with their goal of efficiency. The politicized opposition within the work space of us (end user) and them (management and ERP system) was of course compounded by the inefficiencies resulting from the failures of the non-meaningful training package. Repeatedly, those interviewed throughout the supply train used language and phrasing that symbolically indicated strong feelings of incapability between their own work culture and identity and ERP usage. Many expressed frustration at being compelled to adapt their work processes to fit the system. For example, one middle manager who was forced to use the new system stated: "SAP comes along, far from helping you manage your processes, it tells you you've got to change your processes to suit the information system" (CASE study data).

Apart from meaningful training and clear motivation for change, another core reason for the ERP implementation problems appears to be differences in language styles between the ERP system and the existing culture. The workers have a long history in manual processes and practical application of skills. The language they require to successfully complete these tasks is necessarily practical and concrete, "Information from the right people is more current and accurate than what's in the system" (Case study data). The processes they use are also necessarily concrete and hands-on. And yet the ERP demands a language and process that is abstracted from the lived reality of their normal work functions. The response is very human: a complete lack of trust in the new process and 'language' required to implement it. This in turn then results not in increased efficiency, the key promise of the ERP system, but doubling up of process. For example, operational managers often keep physical quantities of product away from the centralised information system (SAP). An operational manager at the final point of the supply chain states that: "Engineer says - how can we get this [product] in an emergency. We tend to know where [product] is available in what we call "grass stocks" and we can find them in an emergency" (CASE study data). "Grass stocks" are products that are concealed from the main inventory and made available (by people who know where they are located) in times of an emergency. The fact that product is concealed from the main SAP system indicates that in this particular CASE the operational manager has a mistrust of the centralised inventory system. This mistrust of the information system could be due to the operational level employees feeling more comfortable knowing and physically sighting inventory rather than trusting the information system. The end users do not place information "Grass stocks" into the ERP system because of their impression/fear that the ERP may compromise emergency processes. The organizational culture, far from being replaced and determined by the new technology, is actually re-emerging in forms outside the control of the system. 
In effect what is happening is that the use of the ERP system is complied with only ostensibly, and the users see it as an unnecessary hoop through which they now must jump. There is a clear understanding that the ERP is used only by a few operational supervisors and administration people have a concern that data may be incorrect. For example, a manager who took the time to learn how to extract reports from SAP at a more detailed level stated: "They cannot audit their admin people on what they do because they (managers) do not have a clue about SAP so they rely on their admin people totally. They could be plugging in the wrong numbers" (CASE study data). Beyond withholding information from the ERP system, users also develop workarounds (Alter, 2002) to aid end user access to the data embedded within the ERP. As is repeatedly cited in the research, the 'ever present knowledge gap among implementation personnel is usually significant along with [gaps] in organisational member's experience' (Soh, Kien \& Tay-Yap, 2000). An example of this is shown in the quote below where the respondent is having problems with the technology and can only receive useful help from his/her line supervisor who happens to have the necessary level of expertise: "You have got to keep your eye on the whole ballgame otherwise nothing happens. The computer system is something I have always struggled with [...] You basically learn on the job, basically my supervisor [...] is very good on computers and so he's helped me out from that point of view. So if I have a problem with anything I mean there are people in the office [who can help], I say I have a problem with this, I can't get this [done]. Show me how to do it. (CASE study data) [...and...] that's what I find mind boggling is that there are managers out there don't have the faintest [idea] about SAP and are at the whim of their admin people" (CASE study data).

This sporadic rather than complete use of the ERP system within the CASE organization hinders rather than aids efficiency. It creates institutional divisions and results in failure to fully use the system. The existing culture is refusing to be determined by a system that has neither meaning nor motivation for them. A technologically determinist attempt to replace existing practices and languages will necessarily fail as the cultural naturally and organically evades such supplanting strategies. In order to overcome the results of a technologically determinist implementation, we contend that the culture of operational level staff and managerial staff is significantly diverse and that effective IT systems require the input of the end users. In terms of the symbolic messages sent and read within the GOC culture, the refusal by upper management to enact consultative processes in implementation represents mistrust by upper management in their own workers. There is no attempt at open interactive communication concerning the ERP product or implementation and there is a push to supplant existing structures. This is evidenced in the case where a sound operational system was replaced with SAP R/2 so managers could get reports that suited their requirements. This mistrust does not go unnoticed and the workers respond with reticence and non-compliance. Some even prefer to use people to obtain data, rather than trust the system as evidenced by the statement by an operational staff member: "I understand the people I work with but not the systems. You meet a person and you know that you need only tell them once or sometimes twice but with a system it is different and I have not worked that out yet" (CASE study data).

It is very clear that the operational staff feel disempowered by their positions and their current engagement with the system. Frequently managerial instructions and even ERP operations are phrased as 'commands' or 'told' instructions and the speaker's response is recorded as what they 'know', don't know', or 'see' (CASE study data). The use of verbal process verbs for managerial instructions as opposed to mental process verbs for understanding demonstrates some of the latent emotions at work in this situation and also the loss of agency felt by end users. The use of personal pronouns also demonstrates power relations. There is repeated use of non-specified 'us' / 'we' / 'you' versus 'they' 'them' dichotomies again indicative of the perception of unbalanced power relations with the narratives of the interviewees. 
The focus on the people within culture, as opposed to the literal, positivist and technologically determinist functions is vital in understanding problems within ERP implementation. Language and the communication forms that people use are not simply a means to help convey a pre-existing reality; rather, they affect perception of reality. Language then is not just content, it is form; paralanguage, adjective and noun choices, and verb process choices all operate to affect that which we communicate and embedding latent messages and even ideologies (Goatley, 2000). ERP implementation has, at a symbolic level at least, involved ideological competition and communication breakdown within the GOC social system because the intricacies of the existing communication and cultural patterns within the GOC have not been valued or assessed. Returning again to the training stage of the implementation process as an example; it is evident that end users are not simply failing to absorb and understand the content of the training package. They are actively bypassing the information communicated as not meaningful to them. ERP research must avoid technologically determinist emphasis on the benefits of the product. The product, be it training manual or ERP system itself is only functional once incorporated into the culture of the end user. This is true whether the ERP is being implemented into a GOC or a new forming corporate company. But since GOC are more closed and mature and therefore entrenched cultures than young profit seeking organisations it is necessarily harder, and potentially counterproductive, to attempt to change the existing culture rather than adapt to it. And the existing culture must be evaluated and researched according to detailed observation of the complex nuances of the communication practiced and the denotative (literal) and connotative (associated and culturally produced) levels of engagement (Fiske, 1990). The development of ERP implementation, training models, for example, must seek to harmonise with the connotative levels of the language of the existing culture. This is possible through detailed observation of the existing culture and interpretation of verbal feedback through focus on discursive practice and connotative signification.

Significantly, one of the reasons that end users within the GOC are particularly unable to abandon their existing work practices and cultures, thereby inhibiting smooth ERP standardization, seems to lie in the way in which many of the staff link identity and job position. Many of the interview scripts taken can be best understood through what can be termed narrative frameworks. As Alvarez points out, people frequently use narratives to provide unity and structure to their lives and also to characterize, even define, their own identities as the protagonists of their own life story. Alvarez has observed that in the past analysts conducting interviews with end users seek to rush through or evade the story telling/narrative style responses to their questions but in so doing lose key information (Alvarez, 2002).

Understanding the transcripts of users in our CASE as embedded narratives coming from people within an established and embedded culture allows furthering of our understanding of why noncompliance occurs in ERP implementation and use. Firstly this is because many operational level workers do not separate their own subject positioning and feelings of worth from the achievements of the organisation. The position is not simply a job to be done, separate from their culture and identity; it is a culture informing their identity, we can see this implied in the interview transcripts: 'I enjoy coming to work. There's sense of most occasion there's a sense of achievement, we have certain commitments to get out. When we do that I feel good. When I don't do that, I don't feel so good. We meet "better than requirements" for our dispatches for the month, I will take that as a personal pride. If we don't I will take it as something I should have done better" (CASE study data) The impediments to job requirements caused by the failed ERP system are meaning that the end user does not 'feel good' therefore compounding the attitudinal problems causing the ERP implementation difficulties. Secondly, is the importance of linguistic difference realizing difference 'genres', or "language used in performance of particular social practice" (Chouliaraki and Fairclough 1999: 56). The interviews demonstrate repeated moments of the end user constructing meaning 
through narrative style genres, as said above. This is in stark contrast to the technologically determinist 'mandated course of action' style discourse used in ERP implementation processes supported by managerial discourse. This communication dissonance seems to harm end user willingness (even ability) to enter into the system.

It is apparent that the workers also feel an opposition between the technologically determined culture that is being imposed and the existing 'human' culture. Operational workers also feel the necessity in valuing their existing 'cultural' structure, rituals and processes in improving communication. There is some mistrust, fear even, that the technology, far from increasing visibility across the board, will create barriers between 'real' people and impede successful process: "Once you separate people in time and space you have lost a lot so I am not an advocate of technology per se. Going back to the things we mentioned before about personal contacts and trust I believe for communication to be effective, we [need to] communicate face to face, there are a whole lot of other things that are subliminal that affects trust and clarifies things" (CASE study data). The end users are stressing the importance of human communication within the existing social system; research into ERP implementation must follow that lead.

\section{RECOMMENDATIONS}

From the initial interpretation of the interview transcript data from the GOC, it is evident that the problems with ERP implementation include: low training absorption/comprehension; low end user compliance, including work around processes and withholding data; and dissonance between upper managerial and operational levels. This paper has suggested the mature and complex existing culture and communication break down as key reasons for these issues. The authors also stress that it is not fruitful or even possible to resolve these issues by coercing fundamental changes in the existing culture. The research team proposes that further analysis is necessary to clearly define the key components of the existing culture. This will enable better understanding of the IT and IT implementation requirements of the CASE GOC, and potentially other similar organisations. This involves detailed observation of the complex nuances of the communication, practiced and literal and symbolic levels of interaction and meaning production. One example of the outcomes of this process might be the development of training models with detailed and meaningful programs and formats developed in consultation with end users. This might involve the use of narratives and analogy over computerised chains of information delivery. There is also a need to ensure that, at all levels of the implementation life cycle, the end users see the relevance and value of the ERP to work practices and that the change is being integrated into the mores of the existing culture. Implementation must use the symbols of the existing culture to communicate management's valuing of the end user if implementation is to be openly received.

\section{CONCLUSION}

Existing ERP research is strongly positivist in nature and inadequate in terms of providing the perfect solution for corporations to successfully implement ERP systems. This paper contributes to the field of IS research in that it offers a new approach to interpreting the complex clash between the push to use technology to determine the nature of an organisation rather than as a tool of an existing and rich culture. Technological determinism has been explored in terms of its impact on research into ERP implementation. The insight of this paper is not only to reject technological determinist approaches but to identify the technologically determinist tendencies in ERP implementation itself. The push to replace an existing organizational culture rather than consult and assist that culture lies 
at the heart of many ERP implementation failures. Evidence for this hypothesis can be found through careful analysis of interviews with end users. The interviews must be interpreted not just through their blatant ostensible content but through the latent meaning revealed through a range of multi-disciplinary approaches which reveal the rich and potentially productive complexity of the existing culture. In researching ERP implementation in GOC a new approach allows for the rethinking of the issues themselves and promotion of a better understanding of the causes of implementation failures and impediments. Future research will need to adopt cultural studies analysis for the interpretation of end user feedback (interviews) and input on ERP in order to aid prediction of problems and assist future systems development.

\section{REFERENCES}

Alter, S. (2002) Information Systems: The Foundation of e-Business, Prentice Hall, USA.

Anthes, G. H. (2003) Hilton checks into new suite, http://www.computerworld.com/printthis/2003/0,4814,82522,00.html, accessed May 25, 2005.

Alvarez, R. (2002) Discourse Analysis of Requirements and Knowledge Elicitation Interviews Proceedings of the 35th Hawaii International Conference on System Sciences, 2002.

Alvarez, R., and Urla, J. (2002) Using narrative analysis to examine information requirements interviews during ERP implementation Database for Advances in Information Systems, New York:Winter 2002. Vol.33, Iss. 1, pg. 38-52.

Bagchi, B., Kanungo, S., and Dasgupta, S. (2003) Modeling use of enterprise resource planning systems: A path analytic study, European Journal of Information Systems. Basingstoke: June 2003. Vol. 12, iss. 2; pg. 142.

Beekhuyzen, J. (2006 In Press) An Australian Case of ERP Quality: Do Individual Users Matter? in Measuring Information Systems Delivery Quality, E. Duggan \& Reichgelt (Ed). Idea Group Publishing, Pennsylvania, USA.

Bright, K., and Cooper, C.L. (1993) Organisational Culture and the Management of Quality: Towards a new Framework" Journal of Managerial Psychology 8 (6) : 21-27.

Brown, K., Ryan, N. \& Parker, R. (2000) New Modes of Service Delivery in the public sector: Commercializing government services. The International Journal of Public Sector Management Vol. 13 No. 3, 2000, pp206-221.

Chouliaraki, L. \& Fairclough, N. (1999) Discourse in Late Modernity: Rethinking Critical Discourse Analysis Edinburgh University Press, Edinburgh.

Davenport, T.H. (1998) Putting the enterprise into the enterprise system, Harvard Business Review, Vol. 76 No. 4, pp. 121-31

Dooley, L. (2004) AGRIBUSINESS AWARDS: A report for the Rural Industries Research and Development Corporation Monash University October 2004 http://www.rirdc.gov.au/reports/GLC/w04-156.pdf, accessed 28 May, 2005.

Fiske, John. (1990) Introduction into Communication Studies Routledge: London.

Gerrtz, C. Religion as a cultural system. in his The interpretation of cultures. New York: Basic Books.1973 [1966] in Varenne, H.(2002) “Culture Definitions" Communication and Culture, Department of International and Transculturual Studies, Teachers College, Columbia University, http://varenne.tc.columbia.edu/hv/clt/and/culture def.html\#ftop accessed July 10, 2005.

Goatley, A. (2000) Critical Reading and Writing. Routledge, London.

Government Owned Corporations Act (1993) http://www.legislation.qld.gov.au/LEGISLTN/CURRENT/G/GoOwnCorpA93 06C 030328. pdf, accessed May 10, 2005. 
GOC (2005) Office of Government Owner Corporations (Queensland Government) http://www.ogoc.qld.gov.au/ accessed June 252005.

Government Business Enterprises and Public Accountability through Parliament, (1999-2000) http://www.aph.gov.au/library/pubs/rp/1999-2000/2000rp18.htm, accessed May 10, 2005.

Hobson D.P., Kerr D., Burgess, K. \& Houghton, L. (2005) The Inefficiencies and excess's of Enterprise Resource Planning Systems (ERP), The 2005 Standing Conference on Organisational Symbolism XXIII, Excess and Organisation held in Stockholm, Sweden.

Markus, M. L, Petrie, D. and Axline,S. (2000) Bucking the Trends: What the Future May Hold for ERP Packages, Information Systems Frontiers, 2, 2 ( September): 181-193.

Orlikowski, Wanda J. (1992.) The duality of technology : rethinking the concept of technology in organizations. Organizational studies, 3(3):398-427, 1992.

Ross, J. (1999) The ERP Revolution: Surviving versus Thriving, CISR Working Paper No. 307, http://mitsloan.mit.edu/cisr/r-papers.php, accessed May 10, 2005.

Scavo, F. (2005) Benchmarking in Buying and Implementing Enterprise Systems http://www.computereconomics.com/article.cfm?id=1028, accessed May 10, 2005.

Scheer, A.W., \& Habermann, F. (2000) Making ERP a success, Association for Computing Machinery Communications of the ACM New York, April 2000 Vol. 43, Issue 4, P57-61.

Skok, W., and Doeringer, H. (2002) Potential Impact of Cultural Differences on Enterprise Resource Planning (ERP) Projects. Electronic Journal of Information Systems in Developing Nations. 7. 5. 1-8.

Soh, C., Kien, S. S. \& Tay-Yap, J. (2000) Cultural Fits and Misfits, Is ERP a Universal Solution?, 2000 COMMUNICATIONS OF THE ACM April 2000/Vol. 43, No. 4

Smart Business Smart Queensland, Commerce Queensland Blueprint: Smart Policy - Smart Business (2005) http://www.commerceqld.com.au/docs/SmartBusinessSmartQueenslandFULL.pdf, accessed May 10, 2005.

Smith, M. R., and Marx, L. (1994) Does Technology Drive History? The Dilemma of Technological Determinism. Cambridge, Mass.: The MIT Press.

Smircich, L. (1983) Concepts of Culture and Organisational Analysis Administrative Science Quarterly 28 (3): 339-358.

The United States Army, (2005) www.army.mil/aeioo/erp/overview1.html, accessed May 30, 2005.

The US Army Enterprise Solutions Competency Center (2006) ERP Resource center, http://www.army.mil/aeioo/erp/gov.htm, Date accessed 13 February, 2006.

Yin, R.K. (1994). Case study research: Design and methods. Thousand Oaks, CA: Sage Publications. 